Discharge Summaries, Respiratory clinic letter database and the separate patient neurorehab notes was undertaken.

Results One patient has been managed by Basildon Hospital so excluded from the audit which focused on CHUFT services. Of the seven remaining patients, two have not been seen by respiratory services as yet and the reason is unclear. One patient was admitted to Colchester General Hospital with life threatening respiratory compromise two months after referral and started NIV therefore as an inpatient. The final four patients were seen at 13 days, 6 weeks and $(2 \mathrm{x}) 4$ months post referral.

Conclusion There is no standard best practice process for managing these referrals. The NICE quality standard does not advise the time by which these patients should be assessed by respiratory services post referral. The tests required also could be standardised. At present it is not clear whether they require an arterial blood gas or sleep study. It might also be possible to start NIV and assess symptomatic benefit without tests. Writing agreed local guidelines would therefore be beneficial. In light of the patients short prognosis with MND it might advisable to aim for review in $<6$ weeks.

\section{EMAIL ALERTS ALLOW MORE RAPID ASSESSMENT BY PALLIATIVE CARE SERVICE AND DECREASE LENGTH OF HOSPITAL STAY FOR THOSE DISCHARGED HOME}

Hannah Curtis, Rob Smith, Ruth England. Derby Teaching Hospitals NHS Foundation Trust

\subsection{6/bmjspcare-2018-ASPabstracts. 134}

Background The Hospital Palliative Care Team (HPCT) at Royal Derby Hospital identified a number of circumstances where previously known patients were readmitted, but not promptly re-referred, to HPCT. The average length of time between admission to hospital and referral to HPCT was 8 days. We believed earlier HPCT intervention might reduce length of stay.

Methods Through our electronic hospital database we attach an e-alert to a patient's clinical details which generates an email on each re-admission. HPCT apply e-alerts to the records of patients who have stated they would not want further hospital admissions or to those complex patients for whom we feel early involvement in future would be advantageous. We check the e-alert inbox daily and respond by telephoning the ward to ascertain whether HPCT input is required.

Results We report on data collected over 30 months relating to 627 unique patients with e-alerts. 213 patients had unplanned re-admissions to hospital. A total of 294 emails were received, on average 2.25 emails per week - which did not present an excessive new workload. HPCT response time to an e-alert averaged 0.6 days. For those patients whose preference was to be discharged, the use of an e-alert was associated with a reduced time in hospital of 7 days. When the patient died in hospital, the average length of stay was 15 days.

Conclusion Admit alerts allow HPCT to make a more prompt assessment of patients previously known to the service. For patients who go on to be discharged home, this is associated with a decreased length of hospital stay. We suggest this may improve patient experience.

\section{TELEHEALTH PILOT: DEVELOPMENT AND SETTING UP OF A TELEHEALTH SERVICE FOR PALLIATIVE CARE} PATIENTS

Emma Randall. Weldmar HospiceCare, Macmillan

10.1136/bmjspcare-2018-ASPabstracts. 135

Weldmar HospiceCare has growing numbers of patients being referred to the service who want to be supported in their own homes for as long as possible. Weldmar are working in partnership with Macmillan who are providing funding for an 18 month secondment post to set up and lead a Telehealth pilot. Therefore enhancing the service offered to Weldmar patients and giving clinicians another tool to support and monitor patients. Telehealth is already being used in the UK for patients with long term conditions such as COPD and Heart failure but there is limited numbers of palliative care patients using a Telehealth service. The pilot consists of a POD which has a protocol uploaded to it that has been written using recognised palliative care outcome measures these are the Barthel Index and the IPOS scoring system. Patients $\log$ on daily completing the pre-set questions this will monitor changes in symptoms and also level of need. The results are stored on the POD so clinicians visiting the home can access these or clinicians can access these remotely from their PC to review the data the patient has inputted. The PODS have the capability for video conferencing and allow clinicians to use this to discuss with patients the data they have inputted and also carry out assessments of patients face to face via Skype. Patients have embraced the pilot and use of the POD. They report the POD is quick and easy to use, they like that clinicians can monitor them remotely. Clinicians are adapting to having another tool to use to support patients and having access to a wealth of data about patients. Also having the ability to monitor changes in symptoms without being reliant on patients relaying to them how they have been over a set period of time.

\section{DEVELOPING AN ON-LINE TOOLKIT TO SUPPORT END OF LIFE CARE}

Ruth England, Phil Shreeve. Derby Teaching Hospitals NHS Foundation Trust, Treetops Hospice

\subsection{6/bmjspcare-2018-ASPabstracts. 136}

Background When the Liverpool Care Pathway was removed, a range of materials and guidance required review; furthermore, revised practice needed a platform in order to be shared. We decided that our new approach to care might be supported by a novel on-line resource.

Methods A suite of tools that could be used by different providers across Derbyshire at different stages in a patient's end of life journey were collected together. Initially, these documents were held on a webpage hosted by a local community healthcare provider. An accompanying webpage contained details of upcoming educational events and contacts. In the first 6 months the pages were used regularly. However, feedback stated they were not easily accessible to all staff and were clumsy to use. Funding was obtained to build a more 'user friendly' resource. An improved platform (www. 
derbyshire.eolcare.uk) was launched in October 2015. As well as a library of resources, the website offers users the option to create an individualised learning portfolio. This can be linked to existing accredited resources (eELCA) as well as signposting to local face to face educational events.

Results In the period 1.10.2016-30.9.2017, 9862 sessions were conducted on our website, by 5842 users. The average number of pages viewed per session was 3.6 with an average session duration being 3'34 'More than 50\% of users in this period were new to the website and our low bounce rate suggests that people who came to us found what they were looking for. The most popular resource was symptom management guidance.

Conclusions This novel website is a well-used platform for a suite of resources, as well a means of educational support for those engaging in end of life care.

\section{IMPROVING PALLIATIVE CARE AND ADVANCE CARE PLANNING IN END STAGE HEART FAILURE IN A GENERAL HOSPITAL SETTING}

Lori Low, Constantina Pitsillides, Oscar Evans, Eleanor Smith, Adrian Scott, Soon Song. Sheffield Teaching Hospitals

\subsection{6/bmjspcare-2018-ASPabstracts.137}

Background Advance care planning (ACP) is an integral part in the management of end stage heart failure (HF). This is often poorly done in medical wards. To improve this aspect of care, we focussed on discussions with patients and their families regarding prognosis and ceiling of care, explored patients' wishes for end of life care including hospital admission avoidance, liaised with palliative care team on pre-emptive medications for treatment in community and communicated with GPs on advance care management. This study presents the outcomes of these interventions.

Methods End stage HF was defined as patients with severe refractory symptoms (New York Heart Association class 3 and 4) despite optimal medical treatment. This diagnosis was confirmed by echocardiogram and clinical assessment by $\mathrm{HF}$ team. The following interventions were used to improve ACP: training at departmental induction meeting to identify end stage HF patients;

medical teams encouraged to initiate ACP discussions; poster to remind junior doctors of the relevant information to include in discharge summaries to GP

Data were extracted from medical records and discharge summaries to assess the impact of these interventions.

Results Data were collected from 63 patients between August 2016 and March 2017. Discussions on prognosis and ceiling of care improved from $8.6 \%$ to $25.0 \%$ and $14.3 \%$ to $28.5 \%$ respectively. There was better communication to GPs on inpatient $(2.8 \%$ to $21.4 \%)$ and community $(8.6 \%$ to $21.4 \%)$ palliative management. Pre-emptive medication prescribing increased from $8.6 \%$ to $14.3 \%$. There was discrepancy in ACP documentation in medical records vs discharge summaries (38.1 vs $25.0 \%)$.

Conclusions Despite improvement in ACP and its communication to primary care, significant gaps still exist. This study highlights the challenges in implementing this aspect of care in acute medical setting. Innovative strategies at trust organisational level are needed to deliver this care more effectively.
111 THE EPIDEMIOLOGY OF THE OUT OF HOURS GENERAL PRACTIONER'S PALLIATIVE WORKLOAD IN SHROPSHIRE

MP Doré, D Willis. Severn Hospice, University of Chester

\subsection{6/bmjspcare-2018-ASPabstracts. 138}

Introduction There is a paucity in information or standards regarding palliative care being performed by the general practioner (GP) out of hours $(\mathrm{OOH})$. The need for evidence is pressing as discussions are held as to whether 24 hour specialist palliative care cover is required, or whether generalists are capable of dealing with emergency $\mathrm{OOH}$ palliative care.

Aim This poster seeks to provide evidence for this discussion by outlining the patient's demographics, the GP's workload, social issues and symptomology encountered. By quantifying the current challenges faced, we can focus on defining what is needed in the future.

Methodology Using Shropshire Doctors Co-operative Ltd (Shropdoc's) recorded data we have collated a representative picture of the palliative care practice over a year period from 161 OOHGP interactions.

Results Palliative care makes $11.5 \%$ of the total OOHGP Home Visits (HV). There is a positively skewed distribution with a median age 81 with $56 \%$ female. Saturday followed by Sunday are the most active days with more HV over the weekend than the rest of the week combined. Overall $56 \%$ of OOHGP HV are for patients who are expected to die within the next 48 hours with $80 \%$ of the symptoms being agitation, secretions and pain in this group. Social issues were documented in $21 \%$ of $\mathrm{HV}$ with multiple concerns highlighted, however adjusting for a prognosis estimated less than 48 hours the focus shifted to family distress ( $3 \mathrm{x}$ more likely) and future planning (5x more likely).

Conclusion The greatest demand is all weekend and from 17:00-21:00 throughout the week. These finding could provide weighting to arguments of provisions of $\mathrm{OOH}$ care. The patients seen are appropriate and the symptomology encountered is heterogeneous but the majority can be distilled to end-of-life emergency symptoms. This highlights the varied and predictable unpredictability of palliative care and a largely unrecognised contribution to social-care and future-planning $\mathrm{OOH}$.

\section{THE TREATMENT, INTERVENTIONS AND HOSPITAL ADMISSIONS AS PART OF THE OUT OF HOURS GENERAL PRACTIONER'S PALLIATIVE WORKLOAD IN SHROPSHIRE}

MP Doré, D Willis. Severn Hospice, University of Chester

10.1136/bmjspcare-2018-ASPabstracts. 139

Introduction There is a paucity in information or standards regarding palliative care being performed by the general practioner (GP) out of hours $(\mathrm{OOH})$. The need for evidence is pressing as discussions are held as to whether 24 hour specialist palliative care cover is required, or whether generalists are capable of dealing with emergency $\mathrm{OOH}$ palliative care.

Aim This poster seeks to provide evidence for this discussion by outlining treatments instigated, interventions made and hospital admissions arranged $\mathrm{OOH}$. By quantifying the challenges faced, we can define what is needed in the future 